\title{
Epilepsy Surgery in Childhood
}

\author{
Valeria L. Muro, Mary B. Connolly
}

\begin{abstract}
Historically, epilepsy surgery has been considered a treatment of last resort. Advances in neuroimaging, particularly high resolution magnetic resonance imaging (MRI) techniques and functional neuroimaging, advances in neuroanesthesia and neurosurgery have all contributed to the development of safe and effective epilepsy surgery in infants and children. Furthermore, epilepsy surgery may prevent the chronic deleterious effects that uncontrolled epileptic seizures have on brain development. The main challenges that clinicians face are early identification of infants and children who have epilepsy which is amenable to epilepsy surgery, the timing of epilepsy surgery and the investigation of patients where no lesion is demonstrable on MRI. It is imperative that children be followed after epilepsy surgery to assess the long-term outcomes not only in relation to seizure control, but also to assess quality of life, psychoeducational achievement, and psychiatric co-morbidity.
\end{abstract}

RÉSUMÉ: Chirurgie de l'épilepsie dans l'enfance. Historiquement, la chirurgie de l'épilepsie était considérée comme un traitement de dernier recours. Les progrès en neuroimagerie, particulièrement les techniques d'imagerie par résonance magnétique de haute résolution (IRM) et la neuroimagerie fonctionnelle, les progrès en neuroanesthésie et en neurochirurgie ont contribué au développement de la chirurgie de l'épilepsie qui est maintenant sûre et efficace chez les nourrissons et les enfants. De plus, la chirurgie de l'épilepsie peut prévenir les effets chroniques délétères que certaines crises épileptiques non contrôlées ont sur le développement du cerveau. Le principal défi que les cliniciens rencontrent sont l'identification précoce des nourrissons et des enfants qui ont une épilepsie traitable chirurgicalement, le moment d'effectuer cette chirurgie et l'évaluation des patients chez qui l'IRM ne détecte pas de lésion. Il est essentiel que les enfants soient suivis après la chirurgie de l'épilepsie afin d'évaluer les résultats à long terme, non seulement quant au contrôle des crises, mais aussi pour évaluer la qualité de vie, le niveau psychoéducatif atteint et les comorbidités psychiatriques.

Epilepsy is the most common neurological disorder in childhood affecting $0.6 \%$ of Canadians and in $75-85 \%$ of individuals the onset is before the age of 18 years ${ }^{1}$. In $30 \%$ or more of individuals with epilepsy, seizures do not respond to medical therapy ${ }^{2,3}$. Treatment resistant epilepsy is currently defined as failure to respond to two or more appropriate antiseizure medications ${ }^{4}$. Uncontrolled seizures in the developing brain may be associated with life long effects on intellectual function, attention and behavior ${ }^{5,6}$. Furthermore, uncontrolled epilepsy is associated with a two to four fold greater mortality rate compared to age matched individuals.

The early identification of children with treatment resistant epilepsy who might benefit from epilepsy surgery is extremely important $^{7}$. The timing of epilepsy surgery to optimize intellectual function in light of brain plasticity is also critical. There is often reluctance among neurologists and pediatricians to consider referral for epilepsy surgery evaluation at an early stage due to the possibility of long-term remission in children treated medically ${ }^{8,9}$. The alternative therapeutic options of dietary therapy using the ketogenic diet, modified Atkin's diet or low glycemic index diet and vagus nerve stimulation are often more appealing to neurologists in light of their less invasive nature in comparison with epilepsy surgery.

However, epilepsy associated with malformations of brain development, hippocampal sclerosis, diffuse hemispheric disorders (Sturge-Weber syndrome, hemimegalencephaly, hemispheric cortical dysplasia, Rasmussen syndrome), tuberous sclerosis complex, hypothalamic hamartomas, brain tumors, and stroke are commonly associated with treatment resistant epilepsy and furthermore are often amenable to successful epilepsy surgery ${ }^{9,10}$.

\section{Types of Epilepsy Surgery}

Surgical procedures performed in children are very similar to those performed in adults with the exception of surgery for diffuse hemispheric disease. However, epilepsy surgery involves extra-temporal lobe structures more commonly in children than adults.

Hemispheric surgery was first reported as a treatment for epilepsy by Krynauw in $1950^{11}$ and since then there have been modifications in the surgical techniques. Anatomic hemispherectomy and hemidecortication are performed infrequently nowadays. There are several functional hemispherectomy procedures but in Canada, the most frequent functional hemispheric surgery performed is that proposed by Dr. Villemure called "peri-insular hemispherotomy"12.This procedure involves creating a window in the insula allowing

\footnotetext{
From the Division of Pediatric Neurology, Department of Pediatrics, British Columbia's Children's Hospital, Vancouver, British Columbia, Canada. Received January 26, 2012. Final Revisions Submitted August 7, 2012. Correspondence to: Mary B. Connolly, Division of Pediatric Neurology, K3-179, Ambulatory Care Building, British Columbia's Children's Hospital, 4480 Oak Street Vancouver, British Columbia, V6H 3V4, Canada.
} 
access to the lateral ventricle. From within the lateral ventricle, the cortex is disconnected from deeper structures. Medial temporal lobe structures are resected and the corpus callosum is divided in its entirety. Hemispheric surgery is performed for diffuse hemispheric disorders such as Sturge-Weber syndrome, large strokes, with or without a porencephalic cyst, malformations of brain development, hemimegalencephaly, Rasmussen's syndrome and rarely for diffuse brain tumors. Hemispheric surgery is very successful when seizures are lateralized to the affected hemisphere and there is complete disconnection of the hemisphere ${ }^{13}$. In various series, up to $70-$ $80 \%$ of patients of patients are seizure free following hemispheric surgery ${ }^{14,15}$.

Lesionectomy and focal cortical resections involve resections of the lesion with or without surrounding epileptogenic cortex. These resections can be confined to one lobe of the brain or multi-lobar. Very large multi-lobar resections are usually performed for malformations which do not involve the entire hemisphere or destructive processes involving several lobes 16 . Surgery for mesial temporal lobe sclerosis, most commonly involves en-bloc resection that includes the mesial temporal lobe structures, parahippocampalgyrus, and often the inferior temporal gyrus ${ }^{17,18}$.

Selective amygdalohippocampectomy is performed in children infrequently, due to the fact that isolated mesial temporal lobe sclerosis is often associated with other pathologies such as focal cortical dysplasia or tumors. Tuberectomy or resection of multiple cortical tubers in children with tuberous sclerosis complex and treatment resistant epilepsy is increasingly performed ${ }^{19,20}$.

Corpus callosotomy which involves division of the corpus callosum, either in its anterior two thirds or in its entirety, is primarily performed in children with disabling seizures which cause them to fall abruptly to the ground, with tonic or atonic seizures. This results in improvement in tonic or atonic seizures in up to $80 \%$ of patients. Other seizures types may also be helped by corpus callosotomy. When it is not possible to adequately lateralize or localize epileptic seizures, corpus callosotomy may assist in lateralization following the procedure. However, with advances in functional neuroimaging techniques (PET) and magentoencephalography (MEG), it is usually not necessary to form a corpus callosotomy for this reason ${ }^{21}$.

Multiple subpial transections was proposed by Morrell in $1989^{22}$ as an epilepsy surgery procedure in order to preserve function in eloquent cortex such as in the language area and the motor area for the hand. This procedure involves division of the horizontal fibers at $5 \mathrm{~mm}$ intervals in the cortex and this is thought to disrupt the epileptic discharges but preserve function. It may be performed with or without cortical resection. A multicentre analysis of multiple subpial transection in 211 patients demonstrated efficacy for both focal and generalized seizures $^{23}$. It has also been used in refractory Rolandic and Sylvian epilepsy and Landau-Kleffner syndrome ${ }^{24}$.

Surgery for hypothalamic hamartomas has gained popularity following successful surgery in the last decade. This procedure can be performed transcallosally, endoscopically or via skull base approach depending on the size of the lesion and the surgeon's experience. Complete resection of the hamartoma and resolution of gelastic seizures is associated with markedly improved neurodevelopmental outcome. Alternatives to resective surgery to the hypothalamus include gamma knife radio surgery. The choice of surgical approach for hypothalamic hamartomas is influenced by the type of epilepsy, the location and size of the lesion and available resources ${ }^{25,26}$.

\section{Selection of Surgical Candidates}

Phase I of the pre-surgical evaluation begins with a careful review of the clinical history. Details of the pregnancy, perinatal history, presence of febrile seizures, status epilepticus, central nervous system infection and brain trauma are associated with certain types of brain pathology. Review of neurodevelopment milestones, handedness and intellectual function are very important in children. Details of the family history, in light of the advances in our understanding of the genetics of epilepsy may allow us to identify genetic epilepsies where surgery would not be recommended such as autosomal dominant frontal lobe epilepsy and autosomal dominant temporal lobe epilepsy.

The neurological examination is often of limited contribution other than in patients with diffuse hemispheric disorders or large structural lesions. Assessment for neurocutaneous abnormalities and visual field examination with formal perimetry are recommended.

Neuropsychological testing and review of prior psychoeducational assessments allows one to determine whether there has been any regression or plateau in cognitive function. Dichotic listening test may be useful to lateralized language but is not specific. In children under the age of three years, who often have continuous or extremely frequent epileptic seizures and epileptiform discharges, formal assessment of their neuropsychological function is often not possible or may have limited value.

Due to the high prevalence of psychiatric co-morbidity in children with epilepsy, it is important to screen children as part of the pre-surgical work up for anxiety, mood, attention and other behavioral disorders. Attention to family history of psychiatric disorders is also important. Screening can be performed by the neurologist, neuropsychologist, or depending on resources, a psychiatrist. A systematic approach to screening for psychiatric co-morbidity pre and post surgery is recommended and there are many excellent resources available $^{27}$.

Review of interictal EEGs and in most cases ictal video-EEG monitoring to document habitual seizures are important. However, if there is a clear structural lesion such as a tumor in the temporal lobe and seizure semiology typical of temporal lobe involvement, it may not always be necessary to perform intensive video-EEG monitoring. High resolution MRI, reconstruction and $1 \mathrm{~mm}$ thick $\mathrm{T} 1, \mathrm{~T} 2$ and FLAIR imaging is necessary ${ }^{28}$.

If there is congruence between the clinical, structural neuroimaging, EEG and neuropsychological data, more extensive investigations may not be required.

However, in cases where there is a lack of congruence or the area of epileptogenesis has not been adequately identified, further investigations using more detailed analysis of MRI data, looking at cortical thickness and functional are warranted ${ }^{29}$.

Neuroimaging studies using positron emission tomography PET or ictal and interictal single-photon emission computed 
tomography (SPECT) and MEG may provide further data regarding the localization of the ictal onset zone. Functional MRI is a non-invasive tool for assessment of language, motor function and the visual pathway and memory ${ }^{30,31}$. Children as young as six to seven years of age are usually able to co-operate for these studies. Due to the fact that up to $30 \%$ of children with epilepsy may have language in the non-dominant or both hemispheres, knowledge of language lateralization is critical in the decision making for epilepsy surgery ${ }^{32,33}$. Functional MRI studies have replaced sodium amytal testing for language lateralization in children in many centres.

Resources vary from centre to centre and country to country and any surgical candidates can be identified with good quality EEG, high resolution MRI studies.

\section{Phase II}

The decision to proceed to phase II evaluation using subdural grid and/or depth electrodes should be based on a well thought out hypothesis as to a region of epileptogenesis and eloquent brain functions. Subdural and depth electrodes have benefits and limitations. Depth electrodes permit access to deep structures which are difficult to access with subdural grid and strip electrodes, such as mesial frontal lobe, cingulate gyrus and hippocampus. However, with these latter techniques, the risk of bleeding and infection is increased and blood transfusion with it's attendant risks may be needed. High frequency oscillations (HFOs) appear excellent markers for the epileptogenic zone and it has been related to better postsurgical outcome than removing the seizure onset zone, Their potential needs to be assessed by future research ${ }^{34}$.

\section{Complications of Surgery}

Complications of epilepsy surgery are summarized in Table 1. They may be classified as general or non-specific risks applicable to any surgery. Infection risk in epilepsy surgery includes meningitis; however aseptic meningitis due to irritation of the meninges by blood is more common finding and can mimic bacterial meningitis. Symptoms include headache, vomiting, fever, lethargy. This complication should be treated with steroids and typically resolves within several days.

Complications may also be classified as transient or permanent. Transient mutism or dyspraxia has been described after callosotomy and supplementary sensory motor or mesial frontal lobe resections and usually resolve within days to weeks. Permanent complications are related to the lobe of the brain which has been operated on. In temporal and occipital resections visual field defects may be present prior to surgery and thus need to be assessed formally pre and post-operatively. Post-operative deficits include partial quadrantanopsia, quadrantanopsia or hemianopsia. Surgery in the parietal lobe, may occasionally be associated with visuospatial defects, alien hand, or reading deficits. Stroke may complicate surgery in any part of the brain but vulnerable areas include surgery in the insula where the branches of the middle cerebral artery are vulnerable to damage. During corpus callosotomy, the anterior communicating artery is also vulnerable as it is located just above the corpus callosum and damage to this vessel may result in weakness of the contralateral leg. Large hemispheric surgeries are associated with hemiparesis and hemianopia but these deficits are commonly present in patients with diffuse hemispheric disorders prior to surgery. Damage to the dominant hemisphere, if speech is located in the dominant hemisphere, will result in a deterioration in speech but if the surgery is performed in young children, language will transfer to the contralateral hemisphere.

Surgery in infants and children under the age of three years is particularly challenging ${ }^{35}$. In infancy, the blood volume is very low and the risk/benefit ratio of major surgery in this age group needs to be very carefully considered. It is critically important to have anesthesia and intensive care expertise in the management of infants and very young children. Brain swelling may occur particularly with hemimegalencephaly and surgeons may choose to resect a larger area than they would typically do a peri-insular hemispherotomy. This is to facilitate any swelling that may occur in the post-operative period. Blood transfusion may be

Table: Complications of Epilepsy Surgery

\begin{tabular}{ll}
\hline General Complications & Specific Complications \\
Infection & Visual field defects \\
Bleeding & Stroke due to damage of arterial or venous system \\
Anesthetic complications & Early post-operative seizures \\
Aseptic meningitis & Memory deterioration \\
& Mutism \\
& Dyspraxia \\
& Depression \\
& Psychosis \\
& Mortality \\
\end{tabular}


required in infants and young children undergoing diffuse hemispheric disorders. Despite the risks of surgery in children under the age of three years, our own experience and that of colleagues suggest that surgery is safe and effective in this age group $^{35,36}$. Hypothalamic hamartomas pose special surgical challenges and surgery in this location requires special surgical expertise. Early control of seizures is associated with an improved neuropsychological outcome ${ }^{25}$. Following hypothalamic surgery, diabetes insipidus may occur and may be difficult to manage.

\section{Conclusions}

Epilepsy surgery is effective and safe in the pediatric population when carried out in experienced centers by a pediatric multidisciplinary team. Phase I evaluation involves high resolution MRI studies, video-EEG monitoring, and neuropsychological assessment. Functional MRI and/or MEG may be useful in indentifying eloquent brain functions and areas of epileptogenesis. Functional imaging studies using PET and SPECT are useful if MRI does not demonstrate a clear lesion. Phase II evaluation with invasive EEG electrodes should only be embarked when one has a clear hypothesis to test.

Assessment of psychiatric comorbidity and pre and post surgery is important.

The goals of epilepsy surgery need to be established clearly between the family and the epilepsy surgery team. Long-term follow- up after epilepsy surgery should comprise assessment of seizure outcome, quality of life, and neuropscyhologic and psychiatric co-morbidity.

\section{The Future}

Advancement in technology is helping our understanding of epilepsy and it is progressing at a dizzying pace. There has been an explosion of knowledge in the field of genetics translated in a better genotype of some epileptic syndromes and exploring the genetic basis of malformations of brain development at the gene and cellular level including cellular signaling pathways. The most exciting example is the role of the mTOR pathway in tuberous sclerosis complex ${ }^{37}$. The promising development of inhibitors of signal transduction pathways are currently being investigated and nanotechnology has emerged as an exciting multidisciplinary field promising to provide breakthrough solutions. The mTOR pathway may be central to the pathophysiology of epilepsy in a spectrum of cortical malformations and may serve as a common target for novel therapeutic approaches for epilepsy, including potential antiepileptogenic and disease-modifying therapies ${ }^{38}$.

The advances in MRI techniques, the availability of 7T MRI, advances in EEG with high frequency oscillations will allow a more non-invasive approach to the evaluation for epilepsy surgery. It is important in the area of epilepsy surgery in childhood that we abide by the Hippocratic Oath and first do no harm (primum non nocere).

\section{REFERENCES}

1. Wiebe S, Bellhouse DR, Fallahay C, Eliasziw M. Burden of epilepsy: the Ontario Health Survey. Can J Neurol Sci. 1999 Nov;26(4):263-70.

2. Berg AT, Shinnar S, Levy SR, Testa FM, Smith-Rapaport S, Beckerman B. Early development of intractable epilepsy in children: a prospective study. Neurology. 2001 Jun 12;56(11): 1445-52.

3. Kwan P, Brodie MJ. Early identification of refractory epilepsy. N Engl J Med. 2000 Feb 3;342(5):314-9.

4. Kwan P, Arzimanoglou A, Berg AT, et al. Definition of drug resistant epilepsy: consensus proposal by the ad hoc Task Force of the ILAE Commission on Therapeutic Strategies. Epilepsia. 2010 Jun;51(6): 1069-77.

5. Holmes GL. Epilepsy in the developing brain: lessons from the laboratory and clinic. Epilepsia1997 Jan;38(1):12-30.

6. Ben-Ari Y, Holmes GL. Effects of seizures on developmental processes in the immature brain. Lancet Neurol. 2006 Dec;5(12): 1055-63.

7. Cross JH, Jayakar P, Nordli D, et al. Proposed criteria for referral and evaluation of children for epilepsy surgery: recommendations of the Subcommission for Pediatric Epilepsy Surgery. Epilepsia2006 Jun;47(6):952-9.

8. Cross JH. Epilepsy surgery in children--no longer a last resort. Dev Med Child Neurol2010 Feb;52(2):111-2.

9. Harvey AS, Cross JH, Shinnar S, Mathern BW. Defining the spectrum of international practice in pediatric epilepsy surgery patients. Epilepsia. 2008 Jan;49(1):146-55.

10. Snead OC, 3rd. Surgical treatment of medically refractory epilepsy in childhood. Brain Dev. 2001 Jul;23(4):199-207.

11. Krynauw RA. [Infantile hemiplegia and its treatment by hemispherectomy]. Sem Hop1951 Apr 2;27(25):1091-7.

12. Villemure JG, Rasmussen T. Functional hemispherectomy in children. Neuropediatrics. 1993 Feb;24(1):53-5.

13. Smith SJ, Andermann F, Villemure JG, Rasmussen TB, Quesney LF. Functional hemispherectomy: EEG findings, spiking from isolated brain postoperatively, and prediction of outcome. Neurology. 1991 Nov;41(11):1790-4.

14. Devlin AM, Cross JH, Harkness W, et al. Clinical outcomes of hemispherectomy for epilepsy in childhood and adolescence. Brain. 2003 Mar;126(Pt 3):556-66.

15. Basheer SN, Connolly MB, Lautzenhiser A, Sherman EM, Hendson G, Steinbok P. Hemispheric surgery in children with refractory epilepsy: seizure outcome, complications, and adaptive function. Epilepsia. 2007 Jan;48(1):133-40.

16. Mohamed AR, Freeman JL, Maixner W, Bailey CA, Wrennall JA, Harvey AS. Temporoparietooccipital disconnection in children with intractable epilepsy. J Neurosurg Pediatr. 2011 Jun;7(6): 660-70.

17. Sinclair DB, Wheatley M, Aronyk K, et al. Pathology and neuroimaging in pediatric temporal lobectomy for intractable epilepsy. Pediatr Neurosurg. 2001 Nov;35(5):239-46.

18. Thom M, Mathern GW, Cross JH, Bertram EH. Mesial temporal lobe epilepsy: How do we improve surgical outcome? Ann Neurol. Oct;68(4):424-34.

19. Madhavan D, Schaffer S, Yankovsky A, et al. Surgical outcome in tuberous sclerosis complex: a multicenter survey. Epilepsia. 2007 Aug;48(8):1625-8.

20. Koh S, Jayakar P, Dunoyer C, et al. Epilepsy surgery in children with tuberous sclerosis complex: presurgical evaluation and outcome. Epilepsia. 2000 Sep;41(9):1206-13.

21. Tanriverdi T, Olivier A, Poulin N, Andermann F, Dubeau F. Longterm seizure outcome after corpus callosotomy: a retrospective analysis of 95 patients. J Neurosurg. 2009 Feb;110(2):332-42.

22. Morrell F, Whisler WW, Bleck TP. Multiple subpial transection: a new approach to the surgical treatment of focal epilepsy. J Neurosurg. 1989 Feb;70(2):231-9.

23. Spencer SS, Schramm J, Wyler A, et al. Multiple subpial transection for intractable partial epilepsy: an international metaanalysis. Epilepsia. 2002 Feb;43(2):141-5. 
24. Morrell F, Whisler WW, Smith MC, et al. Landau-Kleffner syndrome. Treatment with subpial intracortical transection. Brain. 1995 Dec;118 ( Pt 6):1529-46.

25. Berkovic SF, Arzimanoglou A, Kuzniecky R, Harvey AS, Palmini A, Andermann F. Hypothalamic hamartoma and seizures: a treatable epileptic encephalopathy. Epilepsia. 2003 Jul;44(7): 969-73.

26. Harvey AS, Freeman JL. Epilepsy in hypothalamic hamartoma: clinical and EEG features. Semin Pediatr Neurol. 2007 Jun;14 (2):60-4.

27. Danielsson S, Viggedal G, Steffenburg S, Rydenhag B, Gillberg C, Olsson I. Psychopathology, psychosocial functioning, and IQ before and after epilepsy surgery in children with drug-resistant epilepsy. Epilepsy Behav. 2009 Feb;14(2):330-7.

28. Gaillard WD, Cross JH, Duncan JS, Stefan H, Theodore WH. Epilepsy imaging study guideline criteria: commentary on diagnostic testing study guidelines and practice parameters. Epilepsia. 2011 Sep;52(9):1750-6.

29. Bernasconi A, Bernasconi N, Bernhardt BC, Schrader D. Advances in MRI for 'cryptogenic' epilepsies. Nat Rev Neurol. 2011 Feb;7 (2):99-108.

30. Seo JH, Holland K, Rose D, et al. Multimodality imaging in the surgical treatment of children with nonlesional epilepsy. Neurology. 2011 Jan 4;76(1):41-8.
31. Minassian BA, Otsubo H, Weiss S, Elliott I, Rutka JT, Snead OC, 3rd. Magnetoencephalographic localization in pediatric epilepsy surgery: comparison with invasive intracranial electroencephalography. Ann Neurol. 1999 Oct;46(4):627-33.

32. Szaflarski JP, Holland SK, Schmithorst VJ, Byars AW. fMRI study of language lateralization in children and adults. Hum Brain Mapp. 2006 Mar;27(3):202-12.

33. Yuan W, Szaflarski JP, Schmithorst VJ, et al. fMRI shows atypical language lateralization in pediatric epilepsy patients. Epilepsia. 2006 Mar;47(3):593-600.

34. Zijlmans M, Jiruska P, Zelmann R, Leijten FS, Jefferys JG, Gotman J. High-frequency oscillations as a new biomarker in epilepsy. Ann Neurol. 2012 Feb;71(2):169-78.

35. Steinbok P, Gan PY, Connolly MB, et al. Epilepsy surgery in the first 3 years of life: a Canadian survey. Epilepsia. 2009 Jun;50 (6): $1442-9$

36. Dunkley C, Kung J, Scott RC, et al. Epilepsy surgery in children under 3 years. Epilepsy Res. 2010 Feb;93(2-3):96-106.

37. Zeng LH, Rensing NR, Wong M. Developing Antiepileptogenic Drugs for Acquired Epilepsy: Targeting the Mammalian Target of Rapamycin (mTOR) Pathway. Mol Cell Pharmacol. 2009 Jan 1;1(3):124-9.

38. Wong M, Crino PB. mTOR and Epileptogenesis in Developmental Brain Malformations. 